\title{
Discussion: Difference in pozzolanic behaviour of Tunisian clays with lime and cement
}

\section{Ahlem Chakchouk}

PhD student, Laboratoire de Chimie Industrielle, Ecole Nationale d'Ingénieurs de Sfax, Sfax, Tunisia

\section{Samir Bouaziz}

Professor, Laboratoire Eau, Energie et Environnement, Ecole Nationale d'Ingénieurs de Sfax, Sfax, Tunisia

\section{Basma Samet}

Professor, Laboratoire de Chimie Industrielle, Ecole Nationale d'Ingénieurs de Sfax, Sfax, Tunisia

\section{G. M. Sadiqul Islam}

PhD student, Department of Civil Engineering, University of Dundee, UK

\section{Contribution by G. M. Sadiqul Islam}

As a $\mathrm{PhD}$ student studying the use of pozzolanic material in concrete construction, the discusser read the recent article by Chakchouk et al. (2012) with interest and would appreciate the authors' consideration of the following questions.

(a) Figure 15 gives the compressive strength of cement paste above $80 \mathrm{MPa}$ at 28 days: is this a special type of cement?

(b) In the same figure, the 90-day cement paste strength is lower than that at 28 days: is there any particular reason for this?

\section{Authors' reply}

Referring to the first question, the cement reported in Chakchouk et al. (2012) is not a special type. It is a typical normal Portland cement, classifiable as Type 1 according to BS EN 197 (BSI, 2011). The strength of the cement paste depends on the ratio of water to cement $(\mathrm{w} / \mathrm{c})$. The consistency of 'normal' paste of such cement has a w/c ratio in the range $0 \cdot 28-0 \cdot 32$. For such $w / c$ values, the 28-day compressive strength is normally between 75 and $100 \mathrm{MPa}$, as also reported elsewhere (e.g. Feldman and Beaudoin, 1976: p. 389, Figure 2).

Referring to the second question regarding the decrease of strength measured at 90 days with respect to that measured at 28 days, this can be justified by the fact that specimens cured in water for 90 days become tougher and swell (their volume increases). Stresses thus arise with the consequent formation of microcracks, leading to a decrease in strength.

\section{REFERENCES}

BSI (2011) BS EN 197-1: 2011: Cement. Composition, specifications and conformity criteria for common cements. BSI, London, UK.

Chakchouk A, Samet B and Bouaziz S (2012) Difference in pozzolanic behaviour of Tunisian clays with lime and cement. Advances in Cement Research 24(1): 11-22, http:// dx.doi.org/10.1680/adcr.2012.24.1.11.

Feldman RF and Beaudoin JJ (1976) Cement Concrete Research 6(3): 389-400. 